\title{
Antiproliferative Activity of Silver Nanoplates on Human Promyelocytic Leukemia Cell Lines
}

\author{
Tatsuya Sakaguchi, Kenta Mine, Fuki Kudoh, Rui Kamada, and Kazuyasu Sakaguchi* \\ Department of Chemistry, Faculty of Science, Hokkaido University, N10 W8, Kita-ku, Sapporo, Hokkaido 060-0810
}

(E-mail: kazuyasu@sci.hokudai.ac.jp)

The physical and chemical properties of silver nanomaterials are highly dependent on their shape and size. Recently, Ag nanoparticles have been reported to be useful for medicinal and pharmaceutical applications including anticancer activity. In this study, we showed that Ag nanoplates possess significantly higher antiproliferative activity on human promyelocytic leukemia cells, HL-60, than spherical nanoparticles. The triangular Ag nanoplates induced apoptosis in the cells and were located in the same subcellular compartment as the spherical Ag nanoparticles.

Silver nanomaterials are frequently used in numerous industries because of their unique optical, ${ }^{1}$ electrical, ${ }^{2}$ and catalytic $^{3}$ properties, and these properties are highly dependent on their shape ${ }^{1,4}$ and size. ${ }^{5,6}$ For this reason, significant research efforts have been directed towards the development of new methods for controlling the shape and size of Ag nanomaterials, and an effective method for preparing triangular Ag nanoplates and nanoparticles was recently reported in the literature. ${ }^{7}$ In addition, Ag nanoparticles have received attention for medicinal and pharmaceutical applications. ${ }^{8,9}$ Notably, Ag nanoparticles have been reported to show antitumor activity towards a variety of different tumor cells, both in vitro and in vivo. ${ }^{10-14} \mathrm{Ag}$ nanoparticles have also been shown to enhance the antitumor effects of chemotherapeutic drugs. ${ }^{15}$ Furthermore, Ag nanoparticles have been reported to interact with the HIV virus and inhibit its ability to infect new cells. ${ }^{16}$ However, only spherical Ag nanoparticles were used in all of these biological assays, and there is an urgent need to analyze the effect of the morphology of these nanomaterials on their biological activity. Herein, we report the effect of the shape of $\mathrm{Ag}$ nanomaterials on their antiproliferative activity.

We analyzed the effect of the shape of silver nanomaterials on their antiproliferative activity towards the human leukemia cell line (HL-60) using the cell viability assay. Triangular Ag nanoplates and spherical Ag nanoparticles were prepared as described by Zhang et al., ${ }^{7}$ and their shapes and sizes were confirmed by transmission electron microscopy (TEM) (Figures 1 and S1). The average length of the perpendicular bisector of the $\mathrm{Ag}$ nanoplates was $22.7 \pm 7.9 \mathrm{~nm}$ and their thickness was $6.8 \pm 0.9 \mathrm{~nm}$; the average diameter of spherical Ag nanoparticles was $16.5 \pm 2.9 \mathrm{~nm}$. HL-60 cells were incubated with various concentrations of the nanoplates and nanoparticles for $48 \mathrm{~h}$ prior to the MTS assay. The results of these experiments showed that the $\mathrm{Ag}$ nanostructures reduced the viability of the HL-60 cells in a dose-dependent manner, as shown in Figure 2. The triangular Ag nanoplates reduced the viability of HL-60 cells to $98.1,71.7$, and $50.5 \%$ of the initial level at concentrations of 60,80 , and $100 \mu \mathrm{g} \mathrm{mL}^{-1}$, respectively, whereas the Ag nanoparticles reduced the viability of HL-60 cells to $91.3 \%$ even at a concentration of $100 \mu \mathrm{g} \mathrm{mL}^{-1}$. These results clearly demonstrated that the triangular Ag nanoplates reduced cell

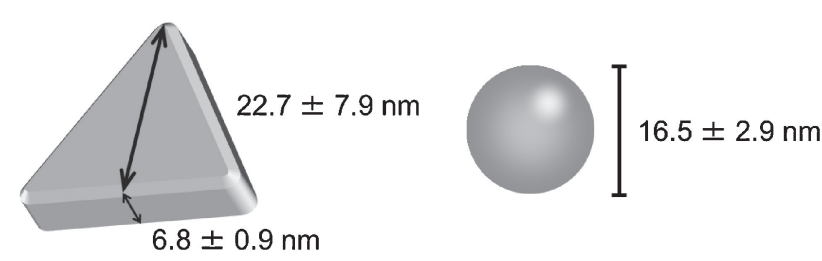

Figure 1. Schematic images of triangular Ag nanoplate (left) and spherical Ag nanoparticle (right). The average length of perpendicular bisector of the nanoplates was $22.7 \pm 7.9 \mathrm{~nm}$ and that thickness was $6.8 \pm 0.9 \mathrm{~nm}$, and the average diameter of the nanoparticles was $16.5 \pm 2.9 \mathrm{~nm}$.

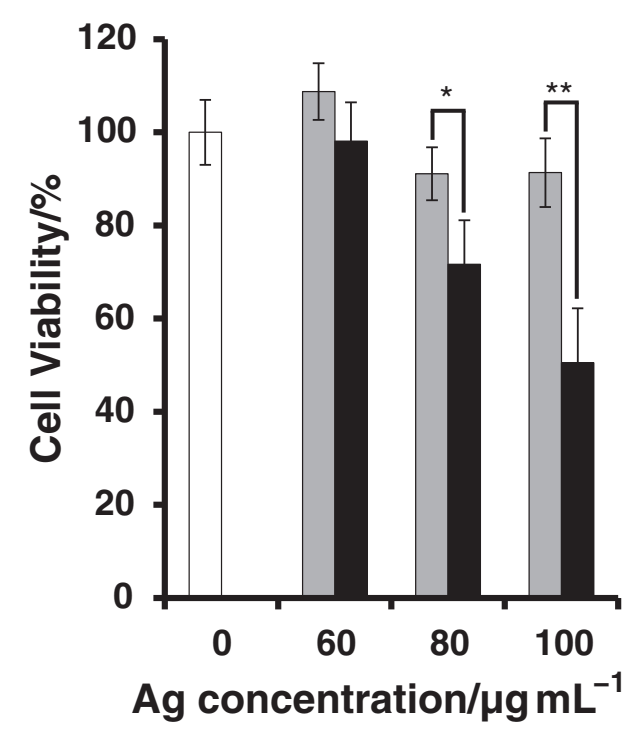

Figure 2. Cell viability of HL-60 cells following the treatment with triangular Ag nanoplates (black) and spherical Ag nanoparticles (gray) at 60,80 , and $100 \mu \mathrm{g} \mathrm{mL}^{-1}$ using an MTS assay. The data have been normalized to make control (white) 100, and shown as the mean values \pm SEM $(n=4)$. Statistical significance was evaluated by $t$-test $\left(*: p<0.10,{ }^{* *}: p<0.05\right)$.

viability to a greater extent than the Ag nanoparticles at all of the concentrations tested, suggesting that the triangular Ag nanoplates can be more effective as an anticancer agent.

To understand the cause of this difference in the antiproliferative activities of these Ag nanostructures, we analyzed the cellular localization of $\mathrm{Ag}$ nanostructures by the use of fluorescent-labeled triangular nanoplates and spherical nanoparticles. Fluorescent-labeled nanoplates and nanoparticles were incubated with HL-60 cells at $60 \mu \mathrm{g} \mathrm{mL}^{-1}$ for $24 \mathrm{~h}$, and the cells were observed under a fluorescent microscope. Hoechst 33342 was also used to stain the cell nuclei. As shown in Figure 3, fluorescence of $\mathrm{Ag}$ nanostructures was detected in the cytoplasm in both triangular Ag nanoplates and spherical Ag nanoparticles. 
(a)

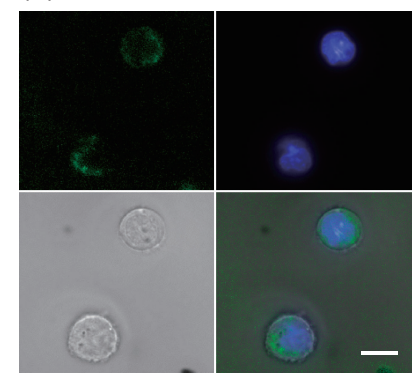

(b)

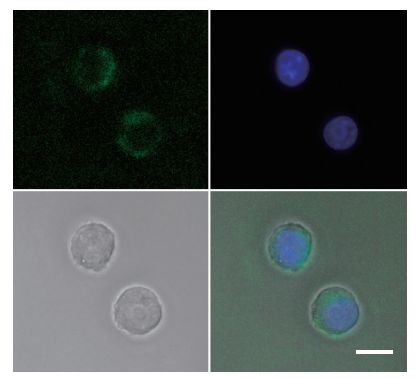

Figure 3. Cellular localization in HL-60 cells of (a) triangular Ag nanoplates and (b) spherical Ag nanoparticles. Upper lefts: fluorescent images by labeled silver nanostructures, upper rights: Hoechst 33342, lower lefts: bright field images, and lower rights: merged images. The scale bar is $10 \mu \mathrm{m}$.

Table 1. Cell cycle distribution of HL-60 cells treated with Ag nanostructures

\begin{tabular}{|c|c|c|c|c|c|c|c|}
\hline \multirow{3}{*}{ Cell cycle } & \multicolumn{7}{|c|}{ Cell cycle distribution $/ \%$} \\
\hline & \multirow{2}{*}{ Control } & \multicolumn{3}{|c|}{$\mathrm{Ag}$ nanoplate $/ \mu \mathrm{g} \mathrm{mL}^{-1}$} & \multicolumn{3}{|c|}{$\mathrm{Ag}$ nanoparticle $/ \mu \mathrm{g} \mathrm{mL}^{-1}$} \\
\hline & & 60 & 80 & 100 & 60 & 80 & 100 \\
\hline sub-G $\mathrm{G}_{1}$ & 12.4 & 23.3 & 37.5 & 44.2 & 16.6 & 22.0 & 26.8 \\
\hline $\mathrm{G}_{1}$ & 53.7 & 49.0 & 40.7 & 36.0 & 46.0 & 48.2 & 43.9 \\
\hline $\mathrm{S}$ & 32.1 & 25.3 & 18.3 & 15.7 & 34.1 & 26.7 & 26.3 \\
\hline $\mathrm{G}_{2} / \mathrm{M}$ & 1.8 & 2.4 & 3.5 & 4.0 & 3.2 & 3.1 & 2.9 \\
\hline super- $\mathrm{G}_{2}$ & 0.1 & 0.0 & 0.0 & 0.0 & 0.0 & 0.0 & 0.0 \\
\hline
\end{tabular}

The results of these experiments revealed that the triangular nanoplates and spherical nanoparticles had both been incorporated into cells and distributed in the cytoplasm.

The effects of $\mathrm{Ag}$ nanostructures on cell cycle were analyzed by standard propidium iodide (PI) staining and flow cytometry. The DNA distribution histogram of HL-60 cells without Ag nanostructures treatment contained one prominent peak, representing cells mainly in the $\mathrm{G}_{1}$ phase (Figure $4 \mathrm{a}$ ). When the cells were treated with $\mathrm{Ag}$ nanostructures for $48 \mathrm{~h}$, a peak appeared for cells in the sub- $\mathrm{G}_{1}$ phase in the DNA distribution histogram, which represented dead cells having undergone apoptosis. As shown in Figure $4 \mathrm{~b}$ and Table 1, $12.4 \%$ of the HL-60 cells not treated with the Ag nanostructures were in the sub- $\mathrm{G}_{1}$ phase. The number of cells in the sub- $\mathrm{G}_{1}$ phase increased slightly to $16.6,22.0$, and $26.8 \%$ following the treating of HL-60 cells with 60,80 , and $100 \mu \mathrm{g} \mathrm{mL}^{-1}$ of the spherical Ag nanoparticles, respectively. In contrast, the number of cells in the sub- $\mathrm{G}_{1}$ phase significantly increased to $23.3,37.5$, and $44.2 \%$ following the treatment of HL-60 cells with 60,80 , and $100 \mu \mathrm{g} \mathrm{mL}^{-1}$ of the triangular $\mathrm{Ag}$ nanoplates, respectively. The number of cells in the sub- $\mathrm{G}_{1}$ phase was significantly higher in the triangular $\mathrm{Ag}$ nanoplates, compared with the spherical $\mathrm{Ag}$ nanoparticles, at all of the concentrations tested. These results clearly indicated that the $\mathrm{Ag}$ nanostructures induced cell death of HL-60 and that the anticancer activities of the Ag nanomaterials are highly dependent on their nanostructures, with the triangular $\mathrm{Ag}$ nanoplates showing stronger antiproliferative activity than the spherical nanoparticles.

Triangular Ag nanoplates showed approximately 1.5-fold greater antiproliferative activity than the spherical Ag nano- (a)

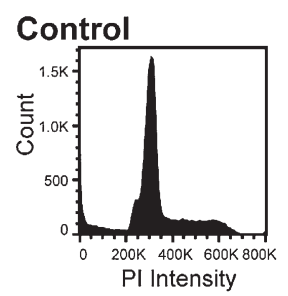

Triangular Ag nanoplates $\left(\mu \mathrm{g} \mathrm{mL}^{-1}\right)$
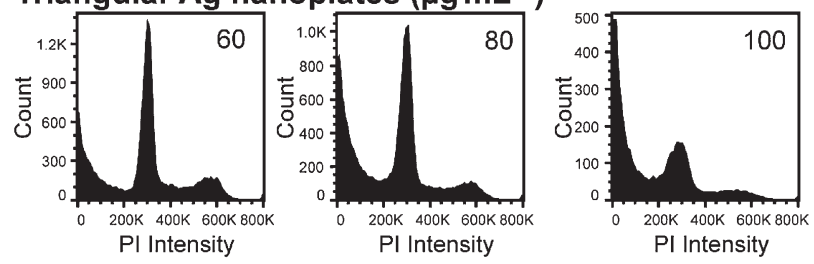

Spherical Ag nanoparticles $\left(\mu \mathrm{g} \mathrm{mL}^{-1}\right)$

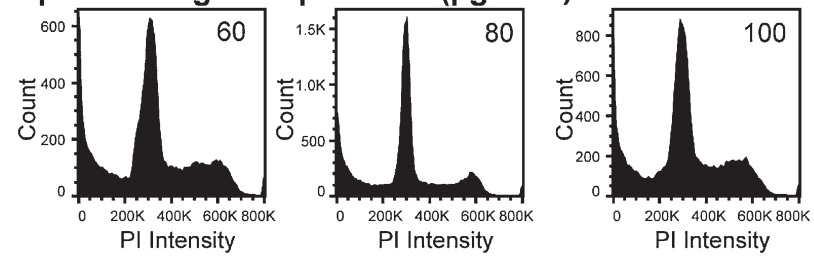

(b)

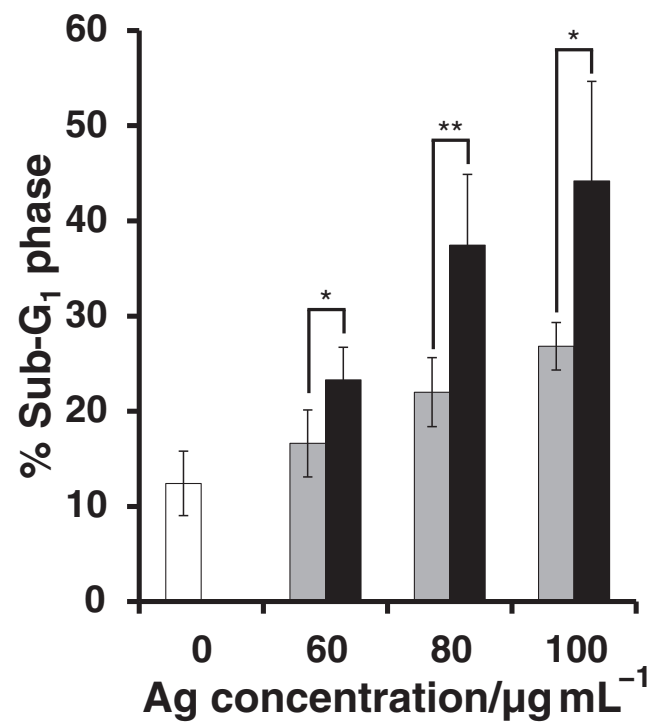

Figure 4. (a) DNA content of Ag nanostructures treated cells was analyzed by flow cytometry. (b) Percentage of cells in the sub- $\mathrm{G}_{1}$ phase after being treated with Ag nanostructures for $48 \mathrm{~h}$. Control (white) with no-Ag treatment, and triangular $\mathrm{Ag}$ nanoplates (black) and spherical Ag nanoparticles (gray) treatments at 60,80 , and $100 \mu \mathrm{g} \mathrm{mL}^{-1}$. Data are shown as the mean values $\pm \operatorname{SEM}(n=3)$. Statistical significance was evaluated by $t$-test $\left(*: p<0.15,{ }^{* *}: p<0.10\right)$.

particles at $100 \mu \mathrm{g} \mathrm{mL}^{-1}$. The intracellular distributions of the triangular nanoplates and spherical nanoparticles were quite similar, and it therefore seemed highly likely that the two different types of $\mathrm{Ag}$ nanostructures were located in the same subcellular compartment and induced cancer cell death in the 
same manner. Ag nanoparticles have been reported to generate reactive oxygen species (ROS) and induce oxidative stress responses, DNA damage, and apoptosis. ${ }^{13,17,18}$ The chemisorption of oxygen onto $\mathrm{Ag}$ is an essential process for the generation of ROS using Ag species. ${ }^{19}$ The chemisorption of oxygen onto an $\operatorname{Ag}(111)$ facet was found to be more stable than it was onto $\mathrm{Ag}(100)$ and -(110) facets. ${ }^{20}$ Truncated triangular silver nanoplates, which include the triangular Ag nanoplates, are mainly enclosed by (111) facets. ${ }^{21}$ Based on these reports, triangular Ag nanoplates might produce ROS more efficiently than spherical Ag nanoparticles, resulting in higher antiproliferative activity. However, further studies will be required to clarify the details of the anticancer mechanism of Ag nanomaterials, including the efficiency of ROS generation as well as the surface area effect.

In summary, we have demonstrated that the antiproliferative activity of Ag nanomaterials is highly dependent on their nanostructure. The results have shown that the shape of Ag nanomaterials plays an important role in determining the strength of their antiproliferative activity, and triangular $\mathrm{Ag}$ nanoplates show a higher activity than spherical Ag nanoparticles. This study should provide new insights and contribute to the design and optimization of $\mathrm{Ag}$ nanostructures for the treatment of cancer.

This work was supported in part by the Grant-in-aid for Scientific Research (B) (No. 24310152) from JSPS (to K.S.), Research Fellowships of the Japan Society for the Promotion of Science for Young Scientists from JSPS (No. 24-2657) (to T.S.).

Supporting Information is available electronically on J-STAGE.

\section{References}

1 S. Link, M. A. El-Sayed, J. Phys. Chem. B 1999, 103, 8410.

2 C. M. Welch, R. G. Compton, Anal. Bioanal. Chem. 2006, $384,601$.

3 R. Schlögl, S. B. Abd Hamid, Angew. Chem., Int. Ed. 2004, 43, 1628.

4 C. Burda, X. Chen, R. Narayanan, M. A. El-Sayed, Chem.
Rev. 2005, 105, 1025.

5 K. L. Kelly, E. Coronado, L. L. Zhao, G. C. Schatz, J. Phys. Chem. B 2003, 107, 668 .

6 I. L. Medintz, H. T. Uyeda, E. R. Goldman, H. Mattoussi, Nat. Mater. 2005, 4, 435.

7 Q. Zhang, N. Li, J. Goebl, Z. Lu, Y. Yin, J. Am. Chem. Soc. 2011, 133, 18931.

8 X. Xu, Q. Yang, J. Bai, T. Lu, Y. Li, X. Jing, J. Nanosci. Nanotechnol. 2008, 8, 5066.

9 M. J. Piao, K. A. Kang, I. K. Lee, H. S. Kim, S. Kim, J. Y. Choi, J. Choi, J. W. Hyun, Toxicol. Lett. 2011, 201, 92.

10 B. Reidy, A. Haase, A. Luch, K. A. Dawson, I. Lynch, Materials 2013, 6, 2295.

11 M. I. Sriram, S. B. M. Kanth, K. Kalishwaralal, S. Gurunathan, Int. J. Nanomed. 2010, 5, 753.

12 J. Liu, Y. Zhao, Q. Guo, Z. Wang, H. Wang, Y. Yang, Y. Huang, Biomaterials 2012, 33, 6155.

13 R. Foldbjerg, D. A. Dang, H. Autrup, Arch. Toxicol. 2011, 85, 743.

14 P. Sanpui, A. Chattopadhyay, S. S. Ghosh, ACS Appl. Mater. Interfaces 2011, 3, 218.

15 R. Thombre, S. Mehta, J. Mohite, P. Jaisinghani, Int. J. Pharm. Bio Sci. 2013, 4, 184.

16 J. L. Elechiguerra, J. L. Burt, J. R. Morones, A. CamachoBragado, X. Gao, H. H. Lara, M. J. Yacaman, J. Nanobiotechnol. 2005, 3, 6 .

17 L. K. Braydich-Stolle, B. Lucas, A. Schrand, R. C. Murdock, T. Lee, J. J. Schlager, S. M. Hussain, M.-C. Hofmann, Toxicol. Sci. 2010, 116, 577.

18 H. Bouwmeester, J. Poortman, R. J. Peters, E. Wijma, E. Kramer, S. Makama, K. Puspitaninganindita, H. J. P. Marvin, Ad. A. C. Peijnenburg, P. J. M. Hendriksen, ACS Nano 2011, 5,4091 .

19 J. Liu, D. A. Sonshine, S. Shervani, R. H. Hurt, ACS Nano 2010, 4, 6903.

20 G. Rovida, F. Pratesi, M. Maglietta, E. Ferroni, J. Vac. Sci. Technol. 1972, 9, 796.

21 S. Chen, D. L. Carroll, Nano Lett. 2002, 2, 1003. 